http://jmscr.igmpublication.org/home/

ISSN (e)-2347-176x ISSN (p) 2455-0450

crossref DOI: https://dx.doi.org/10.18535/jmscr/v8i11.37

Journal Of Medical Science And Clinical Research

\title{
A study on symptoms of Gastro-oesophageal Reflex Disease in correlation with Los-Angeles Classification in Upper GI scopy
}

Authors

Dr Palanikumar.B, ${ }^{1}$ Dr R.Ramesh, ${ }^{2}$ Dr K.Ravichandran, ${ }^{3}$ Dr R.Jayaraman ${ }^{4}$

${ }^{1}$ Junior Resident, ${ }^{2}$ Professor and HOD, ${ }^{3}$ Associate Professor, ${ }^{4}$ Assistant Professor,

Department of General Surgery, Rajah Muthiah Medical College \& Hospital, Annamalai University, Tamil

Nadu, India

\begin{abstract}
Background: Gastro-Oesophageal Reflux Disease (GERD / GORD) is due to pathological reflux of acidic contents from the stomach to the lower oesophagus. It is one the most common upper gastrointestinal disease. The severity of disease can be assessed by the degree of oesophagitis using the Los Angeles Classification.

Aims and Objectives: To assess the correlation between clinical symptoms and endoscopic findings in patients with GERD.

Materials and Methods: A prospective observational study was conducted on 100 patients aged between 18-60 years presenting with symptoms of regurgitation and heartburn. After obtaining ethical committee approval, and getting informed and signed consent from the patients, Upper Gastrointestinal endoscopy was done and severity of Reflux oesophagitis was observed.

Results: Based on the Los Angeles classification, the severity of the disease assessed was Grade A 23\%, Grade B 28\%, Grade C 29\% and grade D 11\%. 9\% of the patients did not have any reflux oesophagitis.

Conclusion: Most patients had mild to moderate reflux oesophagitis as per the Los Angeles Classification. Severity of Oesophagitis increased with increase in duration of symptoms.

Keywords: GERD, Los-Angeles Classification, Upper GI scopy, Reflux oesophagitis.
\end{abstract}

\section{Introduction}

Gastro-Oesophageal Reflux Disease (GERD / GORD) is due to pathological reflux of acidic contents from the stomach to the lower oesophagus. It is one the most common upper gastrointestinal disease. It can be due to various anatomical and physiological factors. Heartburn and Acid Regurgitation are the most commonest symptoms. The severity of disease can be assessed by the observing degree of oesophagitis caused by the reflux and grading it using the Los Angeles Classification.

\section{Materials and Methods}

Prospective observational study was conducted on 100 patients aged between $18-60$ years presenting symptoms of regurgitation and heartburn during the period between August 2018 and January 2020 in Rajah Muthiah Medical College Hospital in Chidambaram. After obtaining ethical committee approval, and getting informed and signed consent from the patients, Upper Gastrointestinal endoscopy was done and severity of Reflux oesophagitis was observed. 


\section{Inclusion Criteria}

$>$ Patients of both sex between age18 - 60 years

$>$ Patients presenting with Complaints of Acid regurgitation and Heart burn

\section{Exclusion Criteria}

Pregnant women

$>$ Patients found to have any growth in stomach on Endoscopy

\section{Los Angeles Classification of Reflex Oesophagitis}

Grade A One (or more) mucosal break no longer than $5 \mathrm{~mm}$ none of which extends between the tops of two mucosal folds.

Grade B One (or more) mucosal break more than $5 \mathrm{~mm}$ long none of which extends between the tops of two mucosal folds.
Grade C One (or more) mucosal breaks that extend between the tops of two or more mucosal folds but which involve less than $75 \%$ of the oesophageal circumference.

Grade D One (or more) mucosal breaks which involve at least $75 \%$ of the esophageal circumference.

\section{Results}

Table 1 Grading of Severity of Reflux Oesophagitis as per Los Angeles Classification

\begin{tabular}{|l|c|}
\hline Grade & Percentage \\
\hline No oesophagitis & $9 \%$ \\
\hline Grade A & $23 \%$ \\
\hline Grade B & $28 \%$ \\
\hline Grade C & $29 \%$ \\
\hline Grade D & $11 \%$ \\
\hline
\end{tabular}

Fig 1: Chart depicting Severity of Reflux Oesophagitis as per Los Angeles Classification

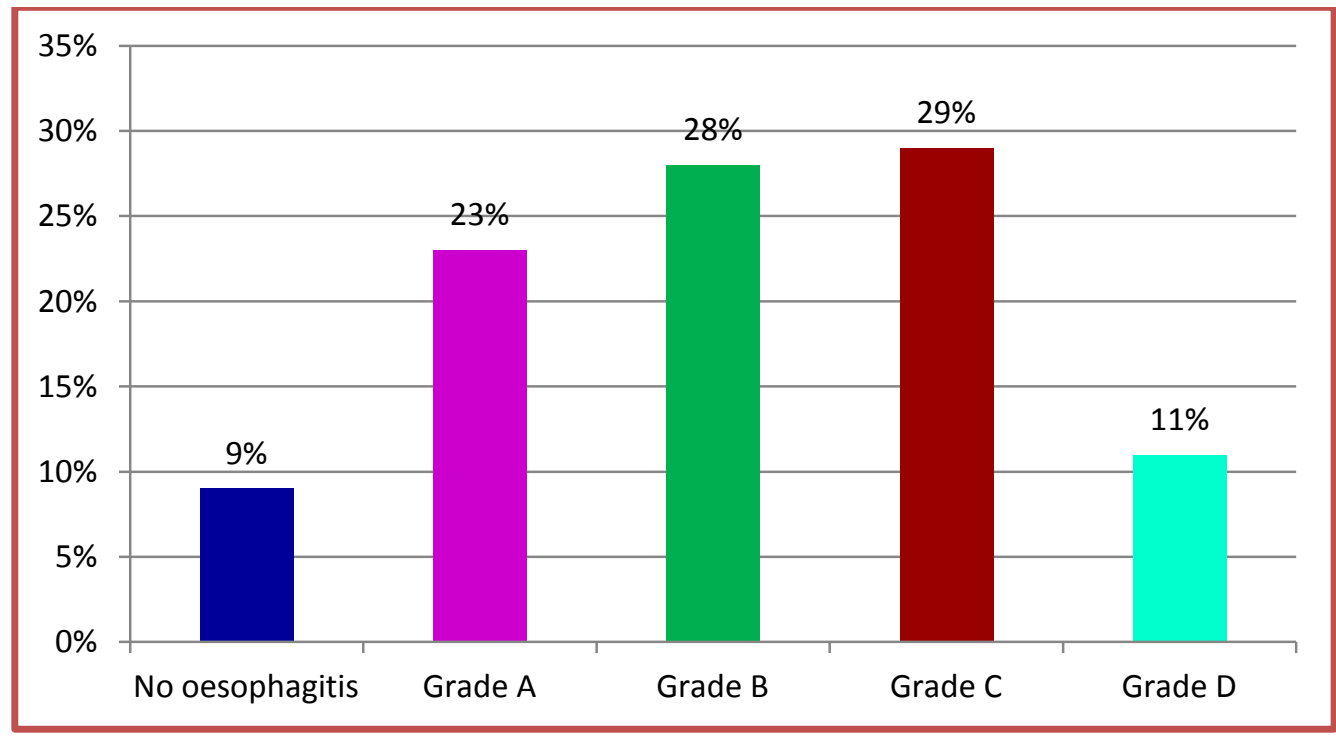

Table 2 Grading in relation to duration of symptoms

\begin{tabular}{|l|c|c|c|}
\hline & 3-6 months & 6-12 months & > 12 months \\
\hline No Oesophagitis & 8 & 1 & 0 \\
\hline A & 11 & 8 & 4 \\
\hline B & 10 & 14 & 4 \\
\hline C & 6 & 12 & 11 \\
\hline D & 2 & 4 & 5 \\
\hline
\end{tabular}




\section{JMSCR Vol||08||Issue||11||Page 219-222||November}

Fig 2 Chart showing Grading in relation to duration of symptoms

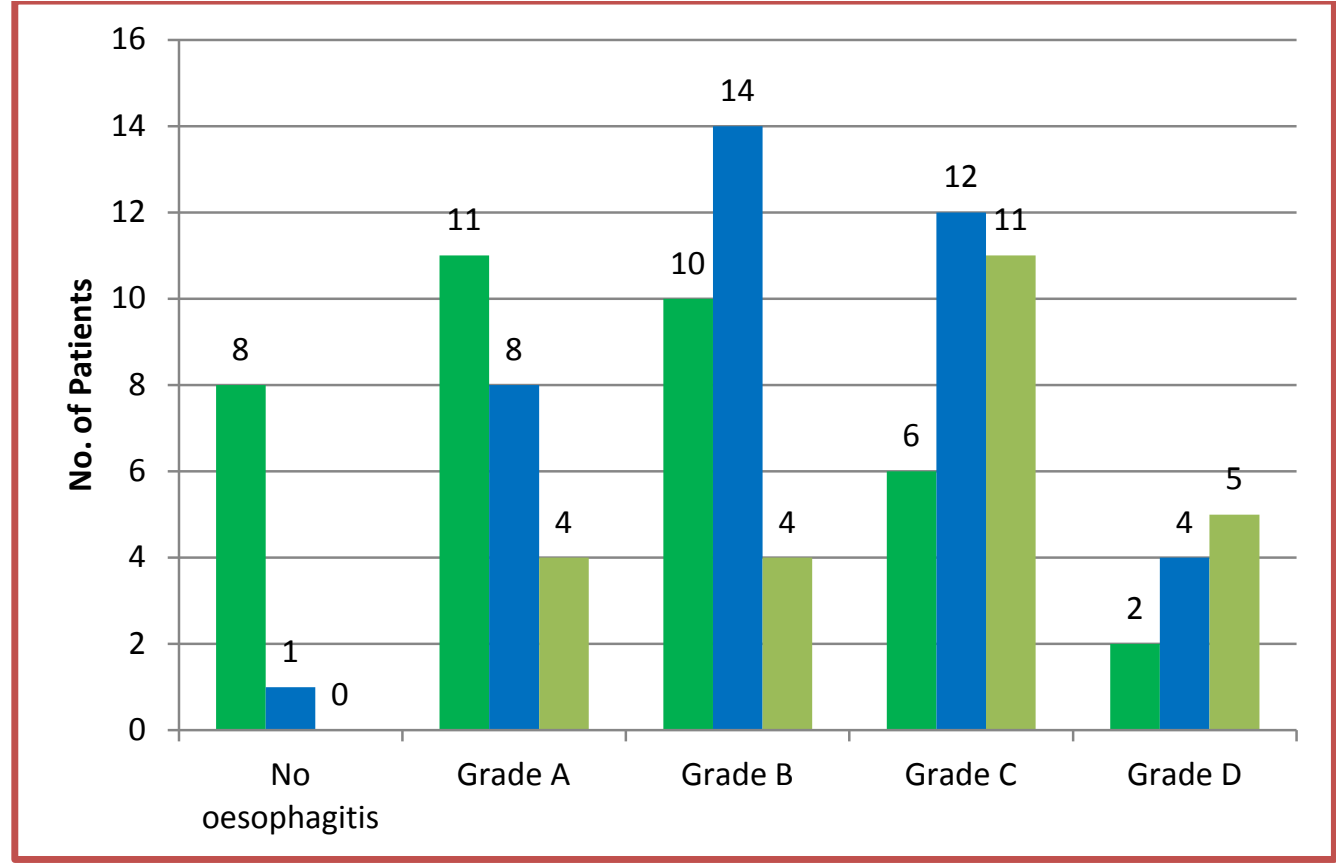

\section{Discussion}

Upper GI endoscopy is a useful tool in assessing the disorders of the oesophagus and stomach. Though manometry $\mathrm{pH}$-impedance monitoring is the gold standard for detection and characterisation of reflux episodes in GERD, it is expensive, not widely available and interpretation is time consuming.

According to the Lyon GERD Consensus of 2017, the Grades C \& D of Los Angeles classification of reflux oesophagitis can be considered as conclusive evidence of GERD and Grades A \& B can be considered as borderline evidence of GERD.

So Upper GI scopy assessment of reflex oesophagitis can be used as a less expensive easier mode of diagnosing GERD. It can also serve to assess the response to treatment by assessing oesophagitis healing.

\section{Conclusion}

Most patients had mild to moderate reflex oesophagitis as per the Los Angeles Classification.

Severity of oesophagitis increased with increase in duration of symptoms.
Declaration of Conflict of Interest: There is no conflict of interest.

Funding: This research received no specific grant from any funding agency in the public, commercial, or not-for-profit sectors.

\section{References}

1. Gyawali CP, Kahrilas PJ, Savarino E, et al. Modern diagnosis of GERD: the Lyon Consensus. Gut 2018;67:1351-1362.

2. Kasyap AK, Sah SK, Chaudhary S (2018) Clinical spectrum and risk factors associated with asymptomatic erosive esophagitis as determined by Los Angeles classification: A cross-sectional study. PLoS ONE 13(2): e019273.

3. Dent, J. Endoscopic Grading of Reflux Oesophagitis: The Past, Present and Future. Best Pract. Res. Clin. Gastroenterol. 2008, 22, 585-599.

4. SS Sami and K Ragunath, The Los Angeles Classification of Gastroesophageal Reflux Disease, Video Journal and Encyclopedia of GI Endoscopy, Volume 1, Issue 1, June 2013, Pages 103-10.

5. Akihito Nagahara et al. Clinical feature of 
asymptomatic reflux esophagitis in patients who underwent upper gastrointestinal endoscopy, Journal of Gastroenterology and Hepatology 27 (2012) Suppl. 3; 53-57.

6. Karthik RC et al. Prevalence of gastro esophageal reflux disease among medical students in Chennai, South India, Indian Journal of Forensic and Community Medicine, July-September 2017;4(3):199203.

7. Gunda Jahnavi, Satya Ranjan Patra, Sarah E. Singh, A study of the symptoms of gastro-esophageal reflux disease and associated risk factors among the rural school children of Veleru India. International Journal of Medicine and Public Health Oct-Dec 2013 Vol 3 Issue 4.

8. Shobna J. Bhatia et al. Epidemiology and symptom profile of gastroesophageal reflux in the Indian population: Report of the Indian Society of Gastroenterology Task Force Indian Journal of Gastroenterology (May-June 2011) 30(3):118-127.

9. J. Punekar, P. Punekar, Manoj K. Malav, Kalpana Chate. Endoscopic evaluation of gastroesophageal reflux disease. International Journal of Contemporary Medical Research 2018;5 (2):B1-B4.

10. V. Raman Muthusamy et al. ASGE Standards of Practice Committee, The role of endoscopy in the management of GERD Gastrointestinal Endoscopy Volume 81, No. $6: 2015$. 